\title{
CAPÍTULO 01: ENSINO DE NANOCIÊNCIA E NANOTECNOLOGIAS NO BRASIL: UMA REVISÃO SISTEMÁTICA
}

\author{
CAPÍTULO 01: ENSEÑANZA DE NANOCIENCIA Y NANOTECNOLOGÍA EN \\ BRASIL: UNA REVISIÓN SISTEMÁTICA
}

\section{CHAPTER 01: TEACHING OF NANOSCIENCE AND NANOTECHNOLOGIES IN BRAZIL: A SYSTEMATIC REVIEW}

\author{
Carlos Alberto da Silva Júnior ${ }^{1}$; Cristhian Rafael Lopes Francisco² ${ }^{2}$ Dosil Pereira de Jesus ${ }^{3}$; Rosiane Lopes da \\ Cunha $^{4}$
}

DOI: https://doi.org/10.31692/978-65-88970-05-8.1-17

\begin{abstract}
RESUMO
A Nanociência e a Nanotecnologia $(\mathrm{N} \& \mathrm{~N})$ estão cada vez mais presentes no cotidiano e têm se destacado em diversas áreas científicas e tecnológicas. A integração desta temática na educação possibilita o desenvolvimento de abordagens interdisciplinares numa diversidade de assuntos. Assim, o objetivo deste trabalho foi apresentar uma revisão da literatura nacional quanto à produção científica no ensino de N\&N. Dentre outros aspectos relevantes, este tipo de análise bibliométrica torna-se meritória na idealização e na implementação de novas políticas públicas. Neste contexto, é importante destacar que a utilização da perspectiva Ciência-Tecnologia-Sociedade-Ambiente (CTSA) auxilia no desenvolvimento social, crítico e científico dos discentes. Metodologicamente a seleção documental, de caráter qualitativo, foi realizada em obras publicadas entre 2006 e agosto de 2020, coletados através das bases de dados SciELO, Google Acadêmico e Web of Science. No total, oito trabalhos foram selecionados, os quais atendiam aos critérios de seleção da pesquisa. Em geral, infere-se que há pesquisas que propõem atividades extracurriculares e experimentos na síntese de nanopartículas, bem como outras que realizam a análise de conteúdo do discurso, tanto de discentes quanto de docentes, por meio de questionários. Concluiu-se que a abordagem de N\&N no ensino ainda é escassa no Brasil. Sendo assim, faz-se necessário que mais estudos sejam concretizados para embasar essa crescente temática.
\end{abstract}

Palavras-Chave: Ensino de nanotecnologia, nanociência, nanopartículas, revisão sistemática, CTSA.

\section{RESUMEN}

La nanociencia y la nanotecnología $(\mathrm{N} \& \mathrm{~N})$ están cada vez más presentes en la vida cotidiana y se destacando en diversas áreas científicas y tecnológicas. La integración de este tema en la educación permite el desarrollo de enfoques interdisciplinarios en una diversidad de materiales. Así, el objetivo de este trabajo ha sido presentar una revisión de la literatura nacional sobre la producción científica en la enseñanza de N\&N. Entre otros aspectos relevantes, este tipo de análisis bibliométrico es relevante en la idealización e implementación de nuevas políticas públicas. En este contexto, es importante destacar que el uso de la perspectiva Ciencia-Tecnología-Sociedad-Medio Ambiente (CTSA) contribuye en el desarrollo social, crítico y científico de los estudiantes. Metodológicamente, la selección documental, de carácter cualitativo, fue realizada en trabajos publicados entre 2006 y agosto de 2020, recogidos a través de las bases de datos SciELO, Google Scholar y Web of Science. En total, se seleccionaron ocho trabajos, que cumplieron con los criterios de selección de investigación. En general, parece que existen investigaciones que proponen actividades extraescolares y experimentos en la síntesis de nanopartículas, así como otras que realizan análisis de contenido del discurso tanto de estudiantes como de profesores, a través de cuestionarios. Se concluyó que la enseñanza de N\&N en Brasil aún es escasa. Por lo tanto, es necesario que se realicen más estudios para apoyar este tema en crecimiento.

Palabras Clave: Docencia de nanotecnología, nanociencia, nanopartículas, revisión sistemática, CTS

\footnotetext{
${ }^{1}$ Doutorando em Química Analítica, Universidade Estadual de Campinas (UNICAMP), c262831

2 Doutorando em Engenharia de Alimentos, Universidade Estadual de Campinas (UNICAMP), c211214@dac.unicamp.br

${ }^{3}$ Doutor e professor, Universidade Estadual de Campinas (UNICAMP), dosil@ unicamp.br

${ }^{4}$ Doutora e professora, Universidade Estadual de Campinas (UNICAMP), rosiane@unicamp.b
} 


\begin{abstract}
Nanoscience and Nanotechnology (N\&N) are increasingly present in everyday life, and they have stood out in several scientific and technological areas. The integration of this theme in education enables the development of interdisciplinary approaches in a diversity of subjects. Thus, the objective of this work was to present a review of the national literature regarding scientific production in the teaching of N\&N. Among other relevant aspects, this bibliometric analysis is worthwhile in the idealization and implementation of new public policies. In this context, it is essential to highlight that the use of the Science-Technology-Society-Environment (STSE) approach helps in the social, critical, and scientific development of students. In a qualitative way, the selection of the articles was carried out to select works published between 2006 and August 2020, using the SciELO, Google Scholar, and Web of Science databases. Eight articles were selected, which have attended the research selection criteria. In general, some research proposed extracurricular activities and experiments in the synthesis of nanoparticles and others that carried out speech content analysis of students and teachers by interviews. We concluded that the teaching of N\&N in Brazil is still scarce. Therefore, more studies must be carried out in the context of N\&N.
\end{abstract}

Keywords: Teaching of nanotechnology, nanoscience, nanoparticles, systematic review, STSE.

\title{
INTRODUÇÃO
}

A Nanociência é o estudo dos materiais na escala nanométrica, enquanto a Nanotecnologia é a aplicação da Nanociência (RAFIQUE et al., 2020; BAYDA et al., 2020). Etimologicamente, a palavra de origem grega "nano" significa "anão" e equivale à bilionésima parte do metro $\left(10^{-9} \mathrm{~m}\right)$. Tanto a Nanociência quanto a Nanotecnologia (N\&N) são interdisciplinares e devem ser abordadas na Educação Básica brasileira, conforme as Orientações Curriculares para o Ensino Médio (BRASIL, 2006) e as Novas Diretrizes Curriculares da Educação Básica (BRASIL, 2013).

$\mathrm{Na}$ literatura, existem diferentes trabalhos científicos em $\mathrm{N} \& \mathrm{~N}$ na área da saúde, cosméticos e no desenvolvimento de equipamentos e materiais inteligentes, como de nanotubos de carbono. Entretanto, a abordagem dessa temática nas salas de aula brasileiras ainda apresenta um tímido crescimento. Desta maneira, Sebastian e Gimenez (2016) defendem o constante desenvolvimento de metodologias para a efetiva aprendizagem das ideias cruciais do nanomundo.

Em geral, os docentes apresentam como maiores dificuldades de implementação deste conteúdo: a falta de formação acadêmica multidisciplinar e a ausência de estratégias e recursos didáticos no ambiente escolar. Entretanto, na visão de Seixas, Calabró e Sousa (2017), o conhecimento científico do professor, como processo de enculturação, é uma produção dinâmica, a qual deve ser constantemente atualizada, independentemente de sua formação inicial. Desse modo, embora haja dificuldades neste percurso docente e limitações na escola, deve-se promover uma educação reflexiva e contextualizada, em tempos de alterações voláteis.

Neste contexto, o objetivo desta pesquisa foi realizar uma análise bibliográfica 
sistemática das principais publicações sobre o Ensino de Nanociência e Nanotecnologia no Brasil.

\section{FUNDAMENTAÇÃO TEÓRICA}

\section{Breve contexto: Nanociência e nanotecnologia no Brasil}

Nesta pesquisa, não pretendemos revisar a história da N\&N no Brasil. Nos últimos anos, essa abordagem mais histórica foi trabalhada por diferentes pesquisadores (NERI, 2011; PLENTZ; FAZZIO, 2013; BAYDA, 2020). Neste tópico, objetiva-se apenas contextualizar os avanços da N\&N no maior país da América do Sul para que o entendimento dos desafios ligados ao seu ensino e aprendizagem possam ser mais bem percebidos.

Na literatura nacional, a N\&N tem se destacado em diferentes campos da ciência, como ilustra a Figura 01. Existem pesquisas em diversos campos, como no reparo de lesões traumáticas de nervos (MARTIN; SIQUEIRA, 2018), na síntese de polímeros biodegradáveis (CAPELEZZO et al., 2018), no desenvolvimento de nanodispositivos de defesa militar (AMARAL et al., 2019) e na reavaliação e atualização do controle de vigilância sanitária de alimentos (BATISTA; PEPE, 2014).

Figura 01: A Nanociência como uma ciência multidisciplinar.

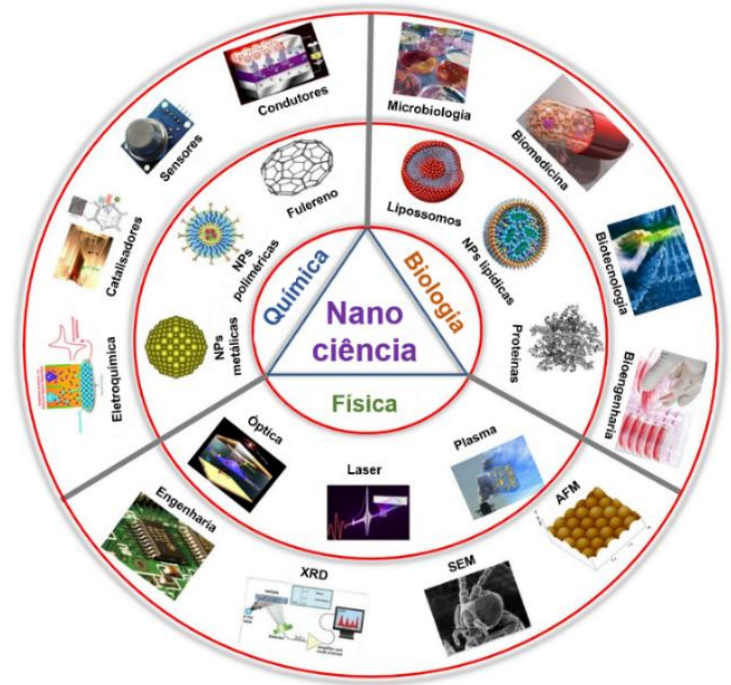

Fonte: Bayda et al. (2020).

Em 2002, o governo brasileiro criou o Programa Nacional de Nanotecnologia, que visava ampliar a abrangência nacional da N\&N e financiar projetos de Pesquisas e Desenvolvimento $(P \& D)$ na área. Desde essa época, outras iniciativas foram surgindo, como o Sistema Nacional de Laboratórios em Nanotecnologias (SisNANO), composto por dezenas de centros de inovação. Entretanto, segundo Plentz e Fazzio (2013), “apesar dos grandes avanços 
nas pesquisas científicas brasileiras, a produção e/ou comercialização de produtos com nanotecnologia nacional ainda são pouco expressivas quando comparadas a países cujas indústrias apresentam elevado grau de desenvolvimento" (PLENTZ, FAZZIO, 2013, p. 25).

Em 2019, institui-se a Iniciativa Brasileira de Nanotecnologia (IBN), como Política Nacional para o Desenvolvimento da Nanotecnologia, visando "criar, integrar e fortalecer ações governamentais na área, com foco na promoção da inovação na indústria brasileira e no desenvolvimento econômico e social" (BRASIL, 2019). Assim, temas como nanossensores, nanomedicina e nanossegurança tornaram-se prioritários.

Em 2020, o projeto de Lei 880/2019 obteve aprovação no Senado Federal. Dentre suas proposições, destacam-se o apoio às empresas nacionais que produzam insumos nanotecnológicos e o incentivo à competição e à produtividade deste mercado (CARVALHO, 2020). Essa proposta legislativa é considerada o Marco Legal da Nanotecnologia no Brasil.

\section{Ciência, Tecnologia, Sociedade e Ambiente - CTSA}

Em geral, a perspectiva Ciência-Tecnologia-Sociedade-Ambiente (CTSA) objetiva:

“(...) formar indivíduos capazes de tomar decisões informadas e responsáveis, reconhecendo e apreciando o papel da ciência e da tecnologia no seu dia a dia. Assume a prioridade da aprendizagem de temas relevantes não só para o aluno, mas também para a sociedade, bem como a aprendizagem dos conceitos científicos a partir de exemplos do dia a dia, tornando a ciência não só mais motivante, mas também mais útil, e o ensino mais contextualizado e atual." (FERNANDES; PIRES; DELGADOIGLESIAS, 2017, p. 1001);

Sendo assim, o movimento CTSA abrange esferas culturais, sociais e tecnológicas, não existindo um modelo único que possa ser aplicado em todas as situações pedagógico-didáticas (PINHEIRO; SILVEIRA; BAZZO, 2007; FERNANDES; PIRES; DELGADO-IGLESIAS, 2017; CREMASCO; PEREIRA; LUCAS, 2017). Nesta perspectiva socioconstrutivista, diversos trabalhos têm sido publicados. Ao entrevistar licenciandos em Química, Dantas e Nunes (2012) concluíram que há pensamentos positivistas em relação à perspectiva CTSA e eles sugeriram a inserção problematizadora de aulas contextualizadas para esses futuros docentes como uma forma de alfabetização científica. Akahoshi, Souza e Marcondes (2018) analisaram a perspectiva desse movimento na produção de unidades temáticas por professores também na área de Química. Os autores concluíram que as propostas metodológicas devem apresentar melhorias em relação ao ensino tradicional, tais como soluções-problema que abordam questões sociais e ambientais, propiciando aos discentes a criação de argumentos próprios na exposição de seus pontos de vista. Stefini e Zoch (2019) inferiram igual conclusão ao utilizarem a água como tema problematizador numa sequência didática. Na área biológica, 
Costa (2016) percebeu que o enfoque CTSA auxiliou no desenvolvimento do ensino de bacteriologia na educação básica e ampliou a conscientização do grau de impacto nas atitudes de cada cidadão no ambiente.

Nestas pesquisas mencionadas, a importância do movimento CTSA se mostra distintamente. Todavia, existem trabalhos nesta perspectiva no ensino de N\&N no Brasil? Se sim, como eles foram desenvolvidos? Antes de responder a essas e outras perguntas em nossos resultados, vamos refletir brevemente sobre a educação no Brasil.

\section{Desafio da Educação Brasileira no Século XXI}

A atual Educação Brasileira precisa estar conectada - efetiva, substancial e processualmente - com os recentes avanços científicos. No contexto da N\&N, novas metodologias precisam ser desenvolvidas para melhor compreensão dos principais avanços nestas áreas. Sob esse viés, "um ensino capaz de formar cidadãos e cidadãs com habilidades para lidar com situações presentes em seus cotidianos ainda é uma das grandes dificuldades enfrentadas pela educação do século XXI" (CARVALHO; WATANABE, 2019, p. 4).

A inserção escolar no nanomundo precisa proporcionar também um protagonismo, afinal o Ensino da N\&N está na vanguarda da pesquisa moderna. Todos precisam não apenas entender as peculiaridades envolvidas nesta área, mas também, conhecer seu papel como agente de transformação. Segundo Figueirêdo et al. (2018), os discentes não devem apenas memorizar mecanicamente uma definição, sem vinculá-la ao seu cotidiano. Os próprios currículos escolares necessitam ser repensados (ZANCAN; SPAGNOLO, 2012), sendo preciso uma nova reestruturação do ambiente escolar, com maior estímulo à reflexão do saber.

Em 2020, a Organização Mundial da Saúde (OMS) declarou a pandemia do COVID19. Diante deste cenário, como relatado por Serafim e Dias (2020), os cientistas têm demonstrado um papel de extrema importância no estudo, combate e prevenção dessa doença infeciosa. Segundo Goergen (1998, p. 53), espera-se que o ambiente escolar "cada vez mais, produza conhecimentos úteis e também forme pessoas capazes de atender aos quesitos de um mundo laboral moldado pelas mesmas ciência e tecnologia". Os resultados desta crise sanitária mundial deixaram perceptível a importância da Educação Brasileira, especialmente em ciências, e como precisamos avançar em contribuições que perpassem as esferas acadêmicas e sociais. 


\section{METODOLOGIA}

Metodologicamente, uma revisão sistemática da literatura e uma análise crítica foram realizadas de forma qualitativa (ESTRELA, 2018; SEVERINO, 2018). O método de análise para seleção quantitativa foi a bibliometria, na qual estas etapas foram seguidas: (1) busca de publicações nas bases de dados Web of Science, SciElo e Google Acadêmico; (2) utilização dos critérios de seleção; (3) extração dos dados obtidos; e (4) análise das pesquisas, conforme ilustra a Figura 02.

Figura 02: Etapas bibliométricas seguidas nesta pesquisa.

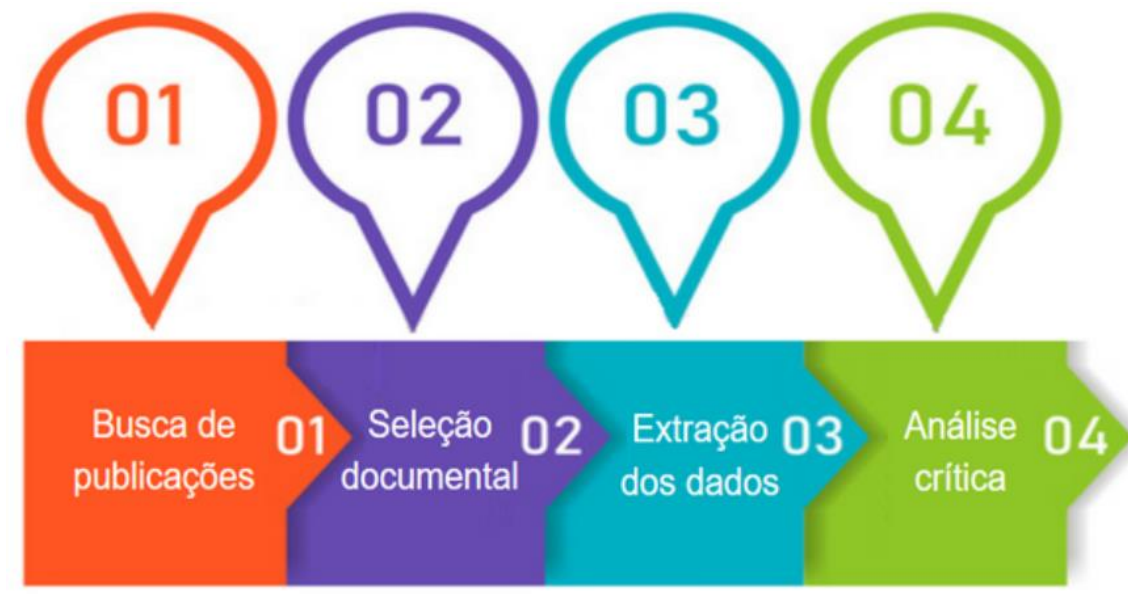

Fonte: Própria (2020).

Os seguintes descritores e combinações foram utilizados, em línguas inglesa e portuguesa: (1) ensino AND nanociência AND Brasil e (2) ensino AND nanotecnologia AND Brasil, utilizando o operador booleano “AND”. A escolha desses descritores e suas combinações foi baseada na sua relevância e no objetivo da pesquisa, além disso, ela se justifica para restrição bibliométrica. Os artigos que retornaram dessa fase exploratória foram avaliados criteriosamente para a seleção daqueles que estivessem dentro do escopo, isto é, aqueles que trabalhavam com o Ensino de N\&N. Esse foi o critério de Seleção Documental. Todas as publicações que não versavam sobre a temática não foram escolhidas. A seleção cobriu o intervalo entre $1^{\circ}$ de janeiro de 2006 a $1^{\circ}$ de agosto de 2020 e se justifica pela a ascensão no Ensino de N\&N nesse período. A pesquisa foi realizada no mês de agosto de 2020.

Este trabalho foi desenvolvido a partir da questão norteadora: como se caracteriza a produção científica disponível na literatura nacional sobre o ensino de nanociência e nanotecnologias nas esferas extraescolar e ensinos fundamental, médio e superior no Brasil? 


\section{RESULTADOS E DISCUSSÃO}

No total, 8 trabalhos científicos foram selecionados, os quais apresentavam, claramente, abordagens no ensino de N\&N. De forma geral, a difusão de conceitos sobre N\&N é realizada através de diferentes perspectivas, em múltiplos contextos e esferas de formação. Sendo assim, é importante destacar que foram analisados tanto estudos de extensão quanto atividades em contexto escolar, como atividades práticas de laboratório e estudos de caso. O Quadro 01 mostra essas publicações.

Quadro 01: Publicações selecionadas nesta pesquisa.

\begin{tabular}{|c|c|}
\hline Título & Autores \\
\hline $\begin{array}{c}\text { Síntese e caracterização de pontos quânticos ambientalmente amigáveis, um } \\
\text { meio simples de exemplificar e explorar aspectos da nanociência e } \\
\text { nanotecnologia em cursos de graduação }\end{array}$ & SANTOS et al., 2020 \\
\hline $\begin{array}{c}\text { Ensino de Nanociência e Nanotecnologia: perspectivas manifestadas por } \\
\text { professores da educação básica e superior }\end{array}$ & $\begin{array}{l}\text { TOMKELSKI; SCREMIN; } \\
\text { FAGAN, } 2019\end{array}$ \\
\hline $\begin{array}{l}\text { The caza-nano game and the teaching of nano-related concepts: ludic } \\
\text { activities at the highschool }\end{array}$ & RIBEIRO et al., 2017 \\
\hline $\begin{array}{l}\text { Uso do método cooperativo de aprendizagem Jigsaw adaptado ao ensino de } \\
\text { nanociência e nanotecnologia }\end{array}$ & LEITE et al., 2013 \\
\hline $\begin{array}{c}\text { Articulação de textos sobre nanociência e nanotecnologia para a formação } \\
\text { inicial de professores de física }\end{array}$ & LIMA; ALMEIDA, 2012 \\
\hline $\begin{array}{c}\text { Preparação de nanopartículas de prata e ouro: um método simples para a } \\
\text { introdução da nanociência em laboratório de ensino }\end{array}$ & MELO JR. et al., 2012 \\
\hline The perception of nanoscience and nanotechnology by children and teenagers & KNOBEL et al., 2010 \\
\hline $\begin{array}{c}\text { Challenges of an exhibit on nanoscience and } \\
\text { nanotechnology }\end{array}$ & $\begin{array}{l}\text { MURRIELLO; CONTIER; } \\
\text { KNOBEL, } 2006\end{array}$ \\
\hline
\end{tabular}

Fonte: Própria (2020)

Murriello, Contier e Knobel (2006) apresentaram uma abordagem interessante na introdução de conceitos de N\&N para crianças e adolescentes em contexto extra-escolar, o qual consistiu na elaboração de uma exibição denominada "NanoAventura", realizada no Musea Exploratório de Ciências da Universidade Estadual de Campinas (Unicamp). Nesse estudo, os autores focaram em descrever as etapas de elaboração, validação e aprimoramento das atividades propostas para serem realizadas pelos visitantes. Dentre as dificuldades encontradas, eles destacaram as barreiras que existem em disponibilizar aos visitantes atividades de fácil visualização sobre um assunto em escala nanométrica, isto é, tamanho invisíyel ao olho nu. Dessa forma, os pesquisadores desenvolveram uma metodologia com jogos eletrônicos, nos quais assuntos como biologia, física e química, atrelados à $\mathrm{N} \& \mathrm{~N}$, pudessem aguçar a 
curiosidade e o interesse por partes dos visitantes, bem como a cooperação entre eles para a execução de tarefas. Murriello, Contier e Knobel (2006) se preocuparam em coletar o depoimento dos visitantes quanto a suas experiências com tais jogos, durante as semanas de exibição. Através dessa avaliação contínua e qualitativa, eles puderam aprimorar-se para promover um maior engajamento dos visitantes nas atividades. Sob um olhar diacrônico, observou-se que a utilização de jogos educativos foi uma forma eficaz de atrair a atenção e entreter os participantes, além de difundir conhecimento sobre N\&N. Nesta perspectiva, Panosso, Souza e Haydu (2015) concluíram que os jogos educativos são instrumentos motivadores na programação de contingências de ensino eficazes.

Como complemento ao estudo descrito anteriormente, Knobel et al. (2010) avaliaram a percepção das crianças e dos adolescentes sobre N\&N com base na exibição "NanoAventura". Os autores coletaram informações sobre o conhecimento dos entrevistados a respeito de $\mathrm{N} \& \mathrm{~N}$ antes e após a participação no evento. Segundo eles, o evento foi moldado para atrair a atenção de crianças e adolescentes para o campo tecnológico, criando um espaço para o aprendizado e entretenimento, com uma abordagem prática através de imagens, música, simulações computacionais e jogos educativos. Verificou-se que antes da participação no evento, ao serem questionados sobre a menor coisa que conheciam, aproximadamente um terço dos entrevistados citaram apenas estruturas em escala macroscópica. Também foi constatado que poucos tinham familiaridade com a palavra "átomo", a unidade básica da matéria (CHANG; GOLDSBY, 2013), e apenas $20 \%$ foram capazes de tentar apresentar definições para termos como molécula, célula e átomo.

Ainda nesse estudo, foi verificada a dificuldade dos entrevistados em assimilar conceitos como escala e tamanho de estruturas comuns na natureza, dificuldade esta que foi trabalhada através da apresentação de um vídeo sobre o tema. Através desse recurso tecnológico, foram apresentados conceitos básicos da $\mathrm{N} \& \mathrm{~N}$, enfatizando, de forma lúdica, a comparação entre o tamanho das estruturas (escalas métrica, micrométrica e nanométrica), principalmente, as biológicas e as não biológicas.

Através desta abordagem, a percepção e a aquisição de conhecimento participantes do evento apresentaram resultados positivos. Como exemplo, após a visita no evento, quando perguntados novamente sobre qual seria a menor coisa que eles conheciam, mais de $80 \%$ dos entrevistados listaram objetos não visíveis a olho nu, dos quais, cerca de 47,9\% se referiram a átomos.

Adicionalmente, Knobel et al. (2010) verificaram que a dificuldade dos entrevistados em citar os componentes básicos de materiais como diamante e grafite, por exemplo, antes do 
evento, foi ligeiramente contornada. Após a participação no "NanoAventura", cerca de $60 \%$ das respostas foram assertivas, valor superior ao inicialmente obtido, o que indicou que mais da metade foi capaz de assimilar o conceito de que a matéria é composta por átomos.

Como conclusão, este estudo apontou a dificuldade de crianças e adolescentes brasileiros em assimilarem conceitos de estrutura e composição da matéria, bem como a noção de escala. Também foi destacado que a difusão de conhecimento sobre N\&N, em eventos como o "NanoAventura", tem mais impacto na formação das crianças do que o simples ato de ler um texto sobre a temática.

Ribeiro et al. (2017) contextualizaram seu trabalho na atual dificuldade de ensino de ciências exatas nas diferentes etapas de formação dos alunos no Brasil, uma vez que a metodologia empregada pela maioria dos professores, infelizmente, se resume apenas a apresentação de fórmulas, que, em geral, não motiva os discentes a estudarem. Nesse contexto, os pesquisadores destacaram a utilização de jogos educativos para introduzir conceitos modernos em sala de aula, como a $\mathrm{N} \& \mathrm{~N}$, de forma a gerar curiosidade nos estudantes para aprenderem assuntos relacionados à ciência contemporânea, que estão presentes no seu cotidiano. Sob esse viés, eles desenvolveram um jogo denominado de "Caza-Nano" para aprimorar o uso da notação científica e da ordem de magnitude e, por meio delas, abordar questões relacionadas ao ensino de $N \& N$.

O “Caza-Nano" foi aplicado para alunos do ensino médio. As atividades e sequências didáticas foram desenvolvidas e aplicadas por discentes bolsistas do Programa Institucional de Bolsa de Iniciação à Docência (PIBID) de Licenciatura em Física do Instituto Federal de Educação, Ciência e Tecnologia de São Paulo (IFSP). Essa ferramenta lúdica é uma estratégia que pode ser usada nas aulas e consiste em palavras criptografadas em um alfabeto, no qual as letras têm uma certa correspondência com representações numéricas. Na visão de Machado (2018), jogos educativos em Física auxiliam no processo de ensino de aprendizagem, porque são instrumentos didáticos capazes de equilibrar a função lúdica e a função educativa.

Leite et al. (2013) enfatizaram a importância de abordar a N\&N no ambiente escolar de maneira mais atrativa, não somente introduzindo seus conceitos em aulas expositivas, mas buscando formas de envolver os alunos, incentivar a interação entre eles e, também/com o professor. Nesta abordagem, os autores utilizaram o método cooperativo de aprendizagem Jigsaw. Ele foi adaptado ao ensino de N\&N, juntamente com a realização de um mínicurso. No total, houve a participação de 80 alunos do ensino médio de uma escola pública da cidade de Porto Ferreira, em São Paulo. Sem pormenorizar, o minicurso compreendeu quatro aulas de 50 minutos cada, sendo que nas três primeiras utilizaram-se recursos audiovisuais e jogos didáticos 
na busca de um ambiente, no qual o estudante assumisse um papel ativo no processo de ensino e aprendizagem.

Na última aula, houve um momento de compartilhamento de conhecimento entre os estudantes através da discussão de um artigo científico, o qual abordava o tema de N\&N. Assim como realizado por Knobel et al. (2010), neste estudo, de forma geral, foram introduzidos os conceitos de escala macro, micro e nanoscópica, apresentando exemplos de estruturas correspondentes a cada escala, bem como os equipamentos utilizados para a sua medição. Ao empregar o método de Jigsaw, a turma foi dividida em grupos base, os quais foram, posteriormente, reorganizados em grupos de especialistas. Em diferentes ocasiões, os discentes deveriam discutir entre si perguntas específicas sobre $N \& N$ relacionadas ao conceito, vantagens e benefícios, por exemplo.

Como resultado, Leite et al. (2013) observaram que, para perguntas conceituais sobre $\mathrm{N} \& \mathrm{~N}$, os alunos utilizaram em suas respostas informações apresentadas no minicurso e no texto científico disponibilizado, resultando em paráfrase do material apresentado, porém, considerouse esse um resultado esperado devido ao caráter técnico das perguntas. No entanto, quando questionados sobre aplicações da $\mathrm{N} \& \mathrm{~N}$, bem como seus possíveis benefícios, muitos apresentaram respostas que não se limitaram apenas ao que estava escrito no texto. Além disso, a maioria do alunado apresentou opiniões críticas relacionadas aos impactos do desenvolvimento da temática em questão nas esferas social, econômica e ambiental. Em geral, verificou-se que a turma refletiu sobre seu papel como cidadãos críticos através do que foi abordado no minicurso, enriquecendo suas conclusões com informações presentes no material didático.

Estudos envolvendo o ensino de N\&N através de experimentos em laboratório têm sido realizados com o objetivo de apresentar na prática exemplos de propriedades físicas interessantes e aplicações tecnológicas de materiais em escala nano. Melo JR. et al. (2012) destacaram o estudo de nanopartículas metálicas, que é um campo de interesse, devido às suas diversas aplicações e propriedades ópticas interessantes.

Neste contexto, os autores reforçaram a necessidade de se abordar essa temática em cursos de graduação em Química no Brasil. De acordo com eles, as aulas experimentais de Química Inorgânica ou de Físico-química são um meio adequado para a introdução de conceitos de N\&N. Salientou-se que esse tema é importante não somente devido ao interesse tecnológico, mas também à possibilidade de, através dessa prática, resgatar conceitos básicos de Química e reforçar conhecimentos previamente abordados. 
De forma geral, esse estudo baseou-se na realização de uma aula prática de 6 horas no laboratório de ensino de Química Inorgânica, na qual os graduandos realizaram a síntese de nanopartículas de prata (AgNPs) e nanopartículas de ouro (AuNPs). Eles também avaliaram a estabilidade das suspensões coloidais das nanopartículas na presença de diferentes agentes desestabilizantes e verificaram a variação de cores em diferentes estados de agregação, uma vez que, ambas características desses sistemas são de grande relevância para o assunto.

Através desse experimento, a turma teve o seu primeiro contato prático com conceitos relacionados à $\mathrm{N} \& \mathrm{~N}$. Os discentes eram concluintes, sendo assim, foi possível a introdução desses conceitos relacionando-os a outros previamente estudados, tais como a diversidade colorimétrica das nanopartículas metálicas, em função do tamanho, com a variação do comprimento de onda em análises espectrofotométricas.

Por ser bastante visual, essa prática foi suficientemente ilustrativa ao ponto de instigar rapidamente os estudantes a desvendarem os fenômenos que ocorreram em escala nanométrica. Melo Júnior et al. (2012) destacaram que o sucesso da realização experimental contribuiu para a aprendizagem de conhecimentos relacionados à escala nano e afirmaram que os relatórios da turma foram bem elaborados e aprofundados conceitualmente.

Seguindo semelhante proposta, Santos et al. (2020) trabalharam com a síntese de pontos quânticos e na introdução de conceitos em N\&N em uma aula prática com graduandos do $8^{\circ}$ período do curso de Química, na Universidade Federal de São João del-Rei (UFSJ). Os pontos quânticos são semicondutores nanocristalinos, que apresentam absorção e emissão na região do visível e regiões próximas, como o ultravioleta e o infravermelho próximo, e que podem ser aplicados como absorvedores em dispositivos conversores de energia solar, emissores de luz, biomarcadores e sensores fluorimétricos, sendo considerados materiais interessantes na área da nanotecnologia, ao mesmo tempo em que podem ser usados para trabalhar diversos tópicos no ensino de N\&N (SANTOS et al., 2020). Reshma e Mohanan (2018) observaram que os pontos quânticos estão entre os avanços mais inovadores do campo biomédico na última década.

No experimento de Santos et al. (2020), a turma sintetizou pontos quânticos de sulfeto de cobre e índio através de um método ambientalmente amigável, os quais foram caracterizados óptica e estruturalmente pelas técnicas de espectroscopia de absorção UV-vis, fotoluminescência de infravermelho e difração de raios X.

De forma geral, os autores destacaram que a realização dessa aula prática possibilitou ao alunado o contato com materiais de grande interesse na área de nanotecnologia através da síntese e caracterização de nanopartículas luminescentes. Neste experimento, os discentes, de 
forma simples, desconstruíram a ideia prévia de que tal procedimento seria de alta complexidade. Santos et al. (2020) ainda verificaram que o experimento atraiu muito o interesse dos alunos por se tratar da síntese de um material que apresenta luminescência na região do visível, quando exposto à radiação ultravioleta.

O estudo realizado por Lima e Almeida (2012) destacou a importância da introdução de N\&N no contexto do ensino médio no Brasil e tratou da avaliação do conhecimento prévio de professores de Física em formação sobre a temática. Os investigadores realizaram um trabalho em sala de aula, dividido em três etapas, com 15 licenciandos de Física. A primeira etapa foi uma entrevista, que objetivou coletar informações a respeito da experiência prévia dos discentes no ensino de Física Clássica e Moderna, bem como suas opiniões sobre o Ensino de Física contextualizado à $\mathrm{N} \& \mathrm{~N}$.

De forma geral, as experiências dos entrevistados apontaram a real dificuldade dos professores de Física: gerar a curiosidade e o entusiasmo dos alunos, uma vez que o ensino tradicional no Brasil se restringe a aulas meramente expositivas com, basicamente, apenas a apresentação de fórmulas. Além disso, as respostas dos licenciandos indicaram um despreparo pessoal em como abordar o ensino de N\&N no ambiente escolar.

$\mathrm{Na}$ segunda etapa, eles trabalharam com diferentes textos relacionados à N\&N, tais como notícias, artigos e livros didáticos. Após uma prévia seleção documental, a turma foi dividida em grupos. Cada equipe redigiu um resumo sobre o texto escolhido para a sua posterior apresentação em forma de seminários. Dessa forma, conceitos e propriedades sobre a N\&N foram discutidos de forma reflexiva, bem como a historicidade dos investimentos científicos na área em discussão. Lima e Almeida (2012), juntamente com a turma, trouxeram a visão da influência do setor econômico sobre as políticas que direcionam as pesquisas científicas e refletiram sobre o papel do cidadão diante de uma sociedade instrumentalizada por inovações tecnológicas, visto que pouco se conhece sobre as consequências do funcionamento das nanotecnologias.

$\mathrm{Na}$ terceira e última etapa, os alunos foram novamente entrevistados e responderam questões relacionadas ao seu conhecimento adquirido a respeito de $N \& N$ e, a partir de então, como eles iriam abordar o ensino de N\&N na condição de educadores. Em geral, observou-se a predisposição da turma em trabalhar conteúdos de N\&N. Em contrapartida, não podem ser esquecidas as dificuldades que eles apontaram, pois, elas sugerem que não serão pequenos os obstáculos que esses futuros docentes enfrentarão para desenvolver tal trabalho.

Recentemente, Tomkelski, Scremin e Fagan (2019) entrevistaram 25 professores de matemática e de ciências da natureza dos ensinos médio e superior, utilizando questionários 
semiestruturados. Ao analisar o discurso desses docentes sobre suas visões da N\&N, os pesquisadores concluíram que existem três formas distintas de abordagem dessa temática no ambiente escolar: (a) trabalho de base para desenvolver um conteúdo, (b) integrado a um conteúdo curricular, e (c) suplementar às atividades de sala de aula.

Nesta pesquisa, aproximadamente $60 \%$ dos educadores nunca haviam trabalhado tópicos de $\mathrm{N} \& \mathrm{~N}$, porque eles afirmaram não possuir conhecimentos suficientes para trabalhar tais abordagens. Apesar dessa alta porcentagem, havia curiosidade pelo tema e pré-disposição para aprofundar seus conhecimentos.

Segundo Tomkelski, Scremin e Fagan (2019, p. 673):

\begin{abstract}
“(...) ao examinarmos as impressões gerais dos professores sobre a abordagem dos tópicos de $\mathrm{N} \& \mathrm{~N}$, evidenciamos posturas contrárias e contraditórias. Contrárias porque há professores que consideram possível abordar estes tópicos tanto no ensino médio quanto superior e outros que acham que não é possível. E contraditória porque alguns professores dizem que nunca abordaram estes assuntos, mas nas suas respostas às questões que versavam sobre as práticas de sala de aula indicam que desenvolvem algumas atividades que contemplam estas perspectivas. Contraditórias, ainda, porque há professores que sugerem que estes tópicos sejam abordados apenas no ensino superior, o que evidencia uma incoerência em relação aos objetivos/práticas da educação escolar e as mudanças advindas das ciências e tecnologias que impactam na vida das pessoas e nas atividades profissionais." (TOMKELSKI, SCREMIN, FAGAN, 2019, p. 673)
\end{abstract}

Por meio desta revisão sistemática, buscamos analisar como estão sendo desenvolvidos os trabalhos no ensino de N\&N no Brasil, principalmente na perspectiva CTSA. A partir do exame realizado, notamos que apesar de existirem algumas pesquisas que sugerem o interesse dos docentes na temática, as abordagens práticas e efetivas ainda são escassas. Sobre esse aspecto, é evidente que muito ainda precisa ser feito, principalmente no viés CTSA, ao mesmo tempo que o país precisa intensificar seus incentivos para promover uma formação mais tecnológica e modificar o perfil tradicional da ação docente. Sob esse viés, segundo Firme e Amaral (2011, p. 384) na perspectiva CTSA sempre será necessária a:

“(...) articulação dos conhecimentos científicos e tecnológicos com o contexto social, tendo como objetivo preparar cidadãos capacitados para julgar e avaliar as possibilidades, limitações e implicações do desenvolvimento científico e tecnológico. (FIRME, AMARAL, 2011, p. 384)

Portanto, além da promoção de letramento científico, faz-se necessária a cooperação científica e educacional com outros países que estão na vanguarda da $\mathrm{N} \& \mathrm{~N}$, como Estados Unidos e Alemanha. Essa conexão pode auxiliar na abertura de novas discussões e troca de informações sobre desafios e soluções em promover um ensino coeso ao século XXI. Sem essas parcerias, o Brasil pode ficar fadado à simples repetição de práticas previamente estudadas em outros países. Afinal, a "cooperação é a melhor forma ou apenas o único meio para alcançar objetivos comuns no mundo globalizado" (SILVA, 2007, p. 6). 
Neste âmbito, a necessidade de uma formação sólida, baseada no conhecimento e na ética, passa a ser uma questão fundamental para o atual sistema educacional e deve ser encarada com um dos grandes objetivos na elaboração de políticas públicas educacionais. Afinal, almejase que o ensino de $N \& N$ no Brasil auxilie no desenvolvimento ético e reflexivo de todos.

\section{CONCLUSÕES}

Nesta revisão científica, pudemos observar os principais estudos conduzidos no Brasil no âmbito do ensino N\&N e avaliar as suas abordagens propostas com enfoque CTSA. Dentre outros aspectos relevantes, este tipo de análise bibliométrica torna-se meritória na idealização e na implementação de novas políticas públicas. Sendo assim, verificou-se que a abordagem de N\&N no ensino ainda é escassa no Brasil, seja através de aulas práticas ou de discussões em grupo para capacitação de futuros professores.

Em alguns estudos, a aprendizagem de conceitos inerentes à $N \& N$ deu-se pela aplicação de jogos educativos, os quais, de forma simples, possibilitaram a inserção de crianças e adolescentes neste nanomundo. Há propostas também na síntese de nanopartículas e no desenvolvimento de atividade extracurriculares, como a visita a museus.

Em suma, as obras avaliadas tratam majoritariamente de temáticas relacionadas à ciência, à tecnologia e ao ensino básico, dando pouco ou nenhum enfoque CTSA na discussão dos efeitos e das consequências da crescente aplicação dos nanomateriais nas esferas social e ambiental. Portanto, o Brasil carece de incentivos para uma disseminação mais interdisciplinar da N\&N na base de formação dos brasileiros, para garantir o desenvolvimento de cidadãos munidos de um conhecimento relevante para a sociedade atual e capazes de agir como pensadores críticos nesse contexto.

\section{REFERÊNCIAS}

AKAHOSHI, L. H.; SOUZA, F. L.; MARCONDES, M. E. R. Enfoque CTSA em materiais instrucionais produzido por professores de química. Revista Brasileira de Ensino de Ciência e Tecnologia, v. 11, n. 3, p. 124-154, 2018.

AMARAL, T. et al. Nanomateriais e dispositivos para a área de Defesa. Revista Ibérica de Sistemas e Tecnologias de Informação, v. 18, p. 409-420, 2019.

BATISTA, A. J. S.; PEPE, V. L. E. Os desafios da nanotecnologia para a vigilância sanitária de medicamentos. Ciência \& Saúde, v. 19, n.7, p. 2100-2105, 2014. 
BAYDA, S. et al. The History of Nanoscience and Nanotechnology: From Chemical-Physical Applications to Nanomedicine. Molecules, v. 25, n. 112, p. 1-15, 2020.

BRASIL, Orientações Curriculares para o Ensino Médio -Ciências da Natureza, Matemática e suas Tecnologias, Brasília: MEC, 2006.

2013.

, Diretrizes Curriculares Nacionais Gerais da Educação Básica, Brasília: MEC,

Portaria $\mathrm{n}^{\circ} 3.459$, de 26 de julho de 2019. Institui a Iniciativa Brasileira de

Nanotecnologia. Diário Oficial da União: seção 1, Brasília, DF, p. 286, 08 ago. 2019.

CAPELEZZO, A. P. et al. Polímero Biodegradável Antimicrobiano através da Aditivação com Compostos à Base de Zinco. Química Nova, v. 41, n. 4, p. 367-374, 2018.

CARVALHO, F. D. R.; WATANABE, G. A Construção do Conhecimento Científico Escolar: Hipóteses de Transição Identificadas a partir das Ideias dos(as) Alunos(as).

Educação em Revista, v. 35, p. 1-26, 2019.

CARVALHO, T. Um importante passo para a Nanotecnologia brasileira a partir do Projeto de Lei 880/2019. NanoEach, São Paulo: USP, 2 mar. 2020. Disponível em: http://www.each.usp.br/nanoeach/?p=2115 Acesso em: 14/09/2020.

CHANG, G. GOLDSBY, K. A. Química. Porto Alegre: AMGH, 2013.

COSTA, S. Ensino de Bacteriologia sob uma Abordagem Ciência, Tecnologia, Sociedade e Ambiente (CTSA) na Educação Básica. Ensino, Saúde e Ambiente, v.9, n. 3, p. 310-334, 2016.

CREMASCO, P. R. P.; PEREIRA, R. S. G.; LUCAS, L. B. Ciência, Tecnologia, Sociedade e Ambiente: Um Olhar a Partir de Algumas Pesquisas. Arquivos do MUDI, v. 21, n. 03, p. 166-177, 2017.

DANTAS, J. M.; NUNES, A.O. As relações ciência-tecnologia-sociedade-ambiente (CTSA) e as atitudes dois licenciandos em química. Educación Química, v. 23, n. 1, p. 85-90, 2012.

ESTRELA, C. Metodologia Científica: Ciência, Ensino, Pesquisa. Porto Alegre: Artes Médicas, 2018.

FERNANDES, I. M. B.; PIRES, D. M.; DELGADO-IGLESIAS, J. Ciência-TecnologiaSociedade--Ambiente nos Documentos Curriculares Portugueses de Ciências. Cadernos de Pesquisa, v. 47, n. 165, p. 998-1015, 2017.

FIGUEIRÊDO, A. M. T. A et al. Experimentação Contextualizada sobre Equilíbrio Químico para Turma de Ensino Médio. International Journal Education and Teaching (PDVL), v. 1, n. 1, p. 91-109, 2018.

FIRME, R. N.; AMARAL, E. M. R. Analisando a implementação de uma abordagem CTS na sala de aula de química. Ciência \& Educação, v. 17, n. 2, p. 383-399, 2011

GOERGEN, P. Ciência, sociedade e universidade. Educação \& Sociedade, v. 19, n. 63, p. 
53-79, 1998.

KNOBEL, $\mathrm{M}$ et al. The perception of nanoscience and nanotechnology by children and teenagers. Journal of Materials Education, v. 32, 2010.

LEITE, I. S. et al. Uso do método cooperativo de aprendizagem Jigsaw adaptado ao ensino de nanociência e nanotecnologia. Revista Brasileira de Ensino de Física, v. 35, n. 4, p. 17, 2013.

LIMA, M. C. A.; ALMEIDA, M. J. P. M. de. Articulação de textos sobre nanociência e nanotecnologia para a formação inicial de professores de física. Revista Brasileira de Ensino de Física, v. 34, n. 4, p. 1-9, 2012.

MACHADO, T. H. Jogos No Ensino De Física: Elaboração De Um Jogo De Cartas Como Abordagem No Ensino De Tópicos De Física Moderna E Contemporânea No Ensino Médio. Curitiba, 2018, 67 p. Monografia (Física). Departamento de Física, Universidade Tecnológica Federal do Paraná (UTFPR), 2018.

MARTINS, R. S.; SIQUEIRA, M. G. Uso da nanotecnologia no reparo das lesões traumáticas de nervos. Brazilian Neurosurgery, v. 26, n.3, p. 111-117, 2018.

MELO JR., M. A. et al. Preparação de nanopartículas de prata e ouro: um método simples para a introdução da nanociência em laboratório de ensino. Química Nova, v. 35, n. 9, p. 1872-1878, 2012.

MURRIELLO, S.; CONTIER, D.; KNOBEL, M. Challenges of an exhibit on nanoscience and nanotechnology. Journal of Science Communication, v. 5, n. 4, 2006.

NERI, D. M. História da Nanociência em Uma Perspectiva Kuhniana: Da invenção dos fulerenos à descoberta do grafeno. Belo Horizonte, 2011. 120 p. Dissertação (História). Faculdade de Filosofia e Ciências Humanas, UFMG, 2011.

PANOSSO, M. G.; SOUZA, S. R.; HAYDU, V. B. Características atribuídas a jogos educativos: uma interpretação Analítico-Comportamental. Revista Quadrimestral da Associação Brasileira de Psicologia Escolar e Educacional, v. 19, n. 2, p. 233-241, 2015.

PINHEIRO N. A. M., SILVEIRA, R.M. C. F., BAZZO, W. A. Ciência, tecnologia e sociedade: a relevância do enfoque CTS para o contexto do ensino médio. Ciência \& Educação, v. 13, n. 1, p. 71-84, 2007.

PLENTZ, F.; FAZZIO, A. Considerações sobre o Programa Brasileiro de Nanotecnologia. Ciência \& Cultura, v. 65, n. 3, p. 23-27, 2013.

RAFIQUE, M. et al. History and fundamentals of nanoscience and nanotechnology, Amsterdam: Elsevier, 2020.

RESHMA, V. G.; MOHANAN, P. V. Quantum dots: Applications and safety consequences. Journal of Luminescence, v. 205, n. 1, p. 287-298, 2018.

RIBEIRO, A.V. et al. The caza-nano game and the teaching of nano-related concepts: ludic activities at the highschool. Revista de Física, n. 54E, p. 79-89, 2017. 
SANTOS, Calink I. L. et al. Síntese e caracterização de pontos quânticos ambientalmente amigáveis, um meio simples de exemplificar e explorar aspectos da nanociência e nanotecnologia em cursos de graduação. Química Nova, v. 43, n. 6, p. 813-822, 2020.

SEBASTIAN, V.; GIMENEZ, M. Teaching Nanoscience and Thinking Nano at the Macroscale: Nanocapsules of Wisdom, Procedia - Social and Behavioral Sciences, v. 228, p. 489-495, 2016.

SEIXAS, R. H. M.; CALABRÓ, L.; SOUSA, D. O. A Formação de professores e os desafios de ensinar Ciências, Revista Thema, v. 14, n. 1, p. 289-303, 2017.

SERAFIM, M. P.; DIAS, R. B. A importância da ciência e das universidades públicas na resolução de problemas sociais. Revista Avaliação, v. 25, n. 1, p. 1-4, 2020.

SEVERINO, A. J. Metodologia do trabalho científico. São Paulo: Cortez Editora, 2018.

SILVA, D. H. Cooperação internacional em ciência e tecnologia: oportunidades e riscos.

Revista Brasileira de Política Internacional, v. 50, n. 1, p. 5-28, 2007.

STEFINI, J. A.; ZOCH, A. N. Utilizando o Tema Água em uma Abordagem CTSA: Uma Sequência Didática para o Ensino de Química. In: COTIAN, L. F. P. (org.), Engenharias, ciência e tecnologia, Ponta Grossa: Atena, v.7, p. 221-232, 2019.

TOMKELSKI, M. L.; SCREMIN, G.; FAGAN, S. B. Ensino de Nanociência e Nanotecnologia: perspectivas manifestadas por professores da educação básica e superior. Ciência \& Educação, v. 25, n. 3, p. 665-683, 2019.

ZANCAN, S.; SPAGNOLO, C. Educação brasileira do século XXI: impasses e desafios da profissão docente. Revista Espaço Acadêmico, v. 12, n. 136, p. 87-94, 2012. 